http://jmscr.igmpublication.org/home/ ISSN (e)-2347-176x ISSN (p) 2455-0450 crossref DOI: https://dx.doi.org/10.18535/jmscr/v8i3.44

\author{
Journal Of Medical Science And Clinical Research \\ IGM Publication \\ An Official Publication of IGM Publication
}

\title{
Multiple Myeloma with Cutaneous Amyloidosis: A Case Report
}

\author{
Authors \\ Dr Harsha ${ }^{1}$, Dr Shama Prakash $\mathrm{K}^{2}$ \\ ${ }^{1}$ Junior Resident, Department of Medicine, K S Hegde Medical Academy \\ ${ }^{2}$ Associate Professor, Department of Medicine, K S Hegde Medical Academy
}

\begin{abstract}
Multiple myeloma is a plasma cell disorder characterized by clonal proliferation and monoclonal immunoglobulin production. The disease manifestations are secondary to direct invasion of plasma cells and excessive light chain production. AL amyloidosis is seen in Multiple myeloma due to light chain deposition. Here we report a case of elderly male presented with multiple swellings and dark pigmentation around both eyes and progressive weakness and stiffness in both limbs diagnosed to have Multiple myeloma with cutaneous and systemic amyloidosis.

Keywords: Multiple myeloma, AL amyloidosis, Cutaneous amyloidosis.
\end{abstract}

\section{Introduction}

Multiple myeloma (MM) is a plasma cell disorder characterized by malignant clonal proliferation of plasma cells producing monoclonal immunoglobulins. MM forms $1 \%$ of all the malignancies and $10 \%$ of all hematological malignancies. The global age standardized incidence rate is 2.1 per million at $95 \% \mathrm{CI}^{1}$. Raising incidence and prevalence of $\mathrm{MM}$ can be attributed to better diagnostic techniques and treatment. It is slightly more common in men than woman with approximately $1.4: 1$ ratio. Median age of diagnosis is 66 years and only $10 \%$ are less than 50 years and $2 \%$ less than 40 years of age $e^{2,3}$. Most of the symptoms of $\mathrm{MM}$ are due to infiltration of plasma cells and excess light chains. Immunoglobin light chain (AL) amyloidosis where in monoclonal light chains deposit in various organs can be seen in patients with MM. Here we report a case of Multiple myeloma with cutaneous and systemic amyloidosis.

\section{Case Report}

A 58 year old gentleman with no previous comorbidities presented to us with multiple round swellings over both eyelids since 6 months and progressive weakness in both lower limbs and stiffness with pain in both hips and knees since 3 months.On examination he was moderately built and poorly nourished, conscious and oriented. He was pale, no lymphadenopathy, no edema. There were multiple nodulopapular swellings on both eye lids which were non tender non pruritic. Conjunctivae were congested with mucopurulent discharge and left eye corneal ulcer. Bilateral knee fixed flexion deformity of $50^{\circ}$, contracture of the hamstring muscles, power in both upper limbs was normal, lower limbs was $4 / 5$, deep tendon reflexes in both lower limbs were sluggish, sensations intact. Abdominal examination revealed no hepatosplenomegaly. Respiratory system cardiovascular system examinations were unremarkable. 
Laboratory Investigations: Severe Anemia with Hemoglobin of $7.7 \mathrm{~g} / \mathrm{dL}$, Total Leucocyte Count of 6300 per cubic millimeter with $86 \%$ neutrophils, $13 \%$ lymphocytes and $1 \%$ eosinophils, Platelet count of 214000 per cubic millimeter and an elevated ESR of 80 millimeters in the first hour. Peripheral blood smear showed, predominantly microcytic hypochromic RBCs with mild anisopoikilocytosis and short rouleaux formations, WBCs were normal in number, with neutrophilic predominance, platelets were adequate and no abnormal cells or hemoparasites. Serum total protein was $8 \mathrm{~g} / \mathrm{dL}$, Albumin: $3.2 \mathrm{~g} / \mathrm{dL}$, Globulin: 4.8g/dL, Albumin/Globulin ration: 0.67, Total Bilirubin: $0.9 \mathrm{mg} / \mathrm{dL}$, Direct Bilirubin 0.37 $\mathrm{mg} / \mathrm{dL}$, AST $61 \mathrm{U} / \mathrm{L}$, ALT $15 \mathrm{U} / \mathrm{L}$ and ALP 127 U/L. Blood Urea $103.2 \mathrm{mg} / \mathrm{dL}$, Creatinine 3.29 $\mathrm{mg} / \mathrm{dL}$, Uric Acid $13.9 \mathrm{mg} / \mathrm{dL}$, Sodium 128 $\mathrm{mmol} / \mathrm{L}$, Potassium $4.25 \mathrm{mmol} / \mathrm{L}$, Serum Calcium $18.5 \mathrm{mg} / \mathrm{dL}$, Urine Analysis showed trace protein, No RBCs, 4-6 WBCs. Serology for HIV, HBsAg and $\mathrm{HCV}$ were negative. LDH was $137 \mathrm{U} / \mathrm{L}$ and Beta-2 Microglobulin $10.84 \mathrm{mg} / \mathrm{L} \quad(0.8-2.2)$. Parathormone was $3.61 \mathrm{pg} / \mathrm{ml}(12-88 \mathrm{pg} / \mathrm{ml})$ and Thyroid Stimulating Hormone was $6.39 \mathrm{ulU} / \mathrm{mL}$. Serum Protein Electrophoresis: Albumin level was normal, and there was significant increase in gamma globulin levels, $M$ spike was noted in gamma region with $M$ band on the electrophoretogram.

Fluorescence in situ hybridization (FISH) analysis of bone marrow aspirate: Negative fir Del 17p (TP53), IgH Gene rearrangement, FGFR3IGH/t $(4 ; 14), \quad$ IGH/MAFB/t(14;20) and IGH$\mathrm{MAF} / \mathrm{t}(14 ; 16)$

Bone Marrow Aspiration cytology showed features of erythroid hyperplasia and multiple myeloma, with $15 \%$ plasma cells. Bone Marrow Biopsy showed features of MM with collections of plasma cells with interstitial pattern of infiltration, along with few binucleated plasma cells and occasional plasma blasts.

MRI Lumbosacral spine with pelvis showed diffuse heterogeneously altered signal intensity involving multiple vertebral bodies. Left paracentral disc extrusion at L4-L5 level indenting the thecal sac and compressing on the left traversing/ exiting nerve root. Disc extrusion with inferior migration at L5-S1 indenting the thecal sac and compressing on the right traversing nerve root. Thickening of bilateral hip joint capsule. Ill defined altered signal intensity focus was noted in head and neck of the left femur measuring around $3.5 \times 2.5 \mathrm{~cm}$, which was hypointense on $\mathrm{T} 2$ weighted sequences and hyperintense on STIR sequences. Ill defined hyperintensity was also noted in the neck of right femur. Loculated fluid signal intensity collection measuring $3 \times 2.7 \mathrm{~cm}$ in the left iliopsoas and another measuring $1 \mathrm{~cm}$ in the right iliacus muscle and ill defined STIR hyperintense signal noted in bilateral iliacus and gluteus muscle.

Eye lid lesion biopsy showed normal epidermis, edematous dermis with multiple epidermal inclusion cysts lined by stratified squamous epithelium containing accumulation of laminated keratin with Congo red positive deposit.

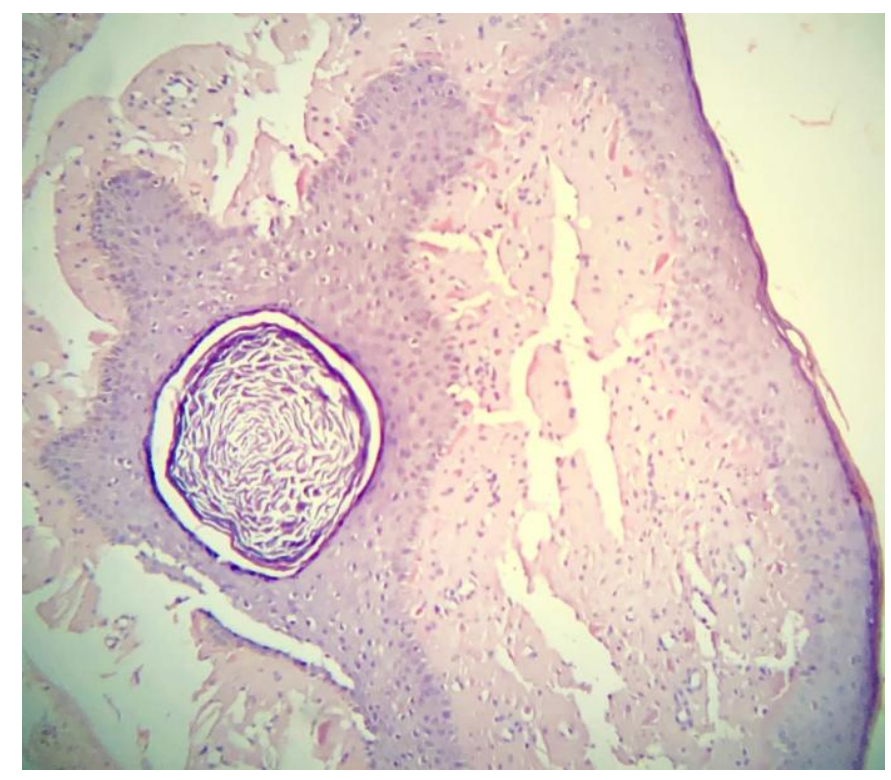

Figure 1: Eye lid biopsy in hematoxylin and eosin stain showing inclusion cyst lined by stratified squamous epithelium containing keratin. 


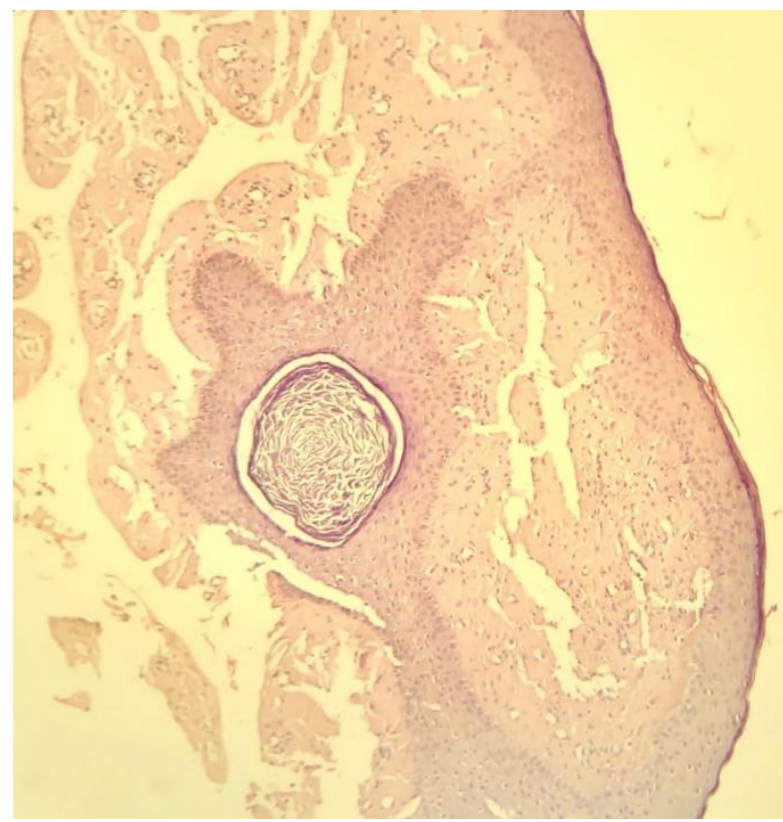

Figure 2: Eye lid biopsy in Congo red stain showing inclusion cyst lined by stratified squamous epithelium containing kertain and congo red positive deposit.

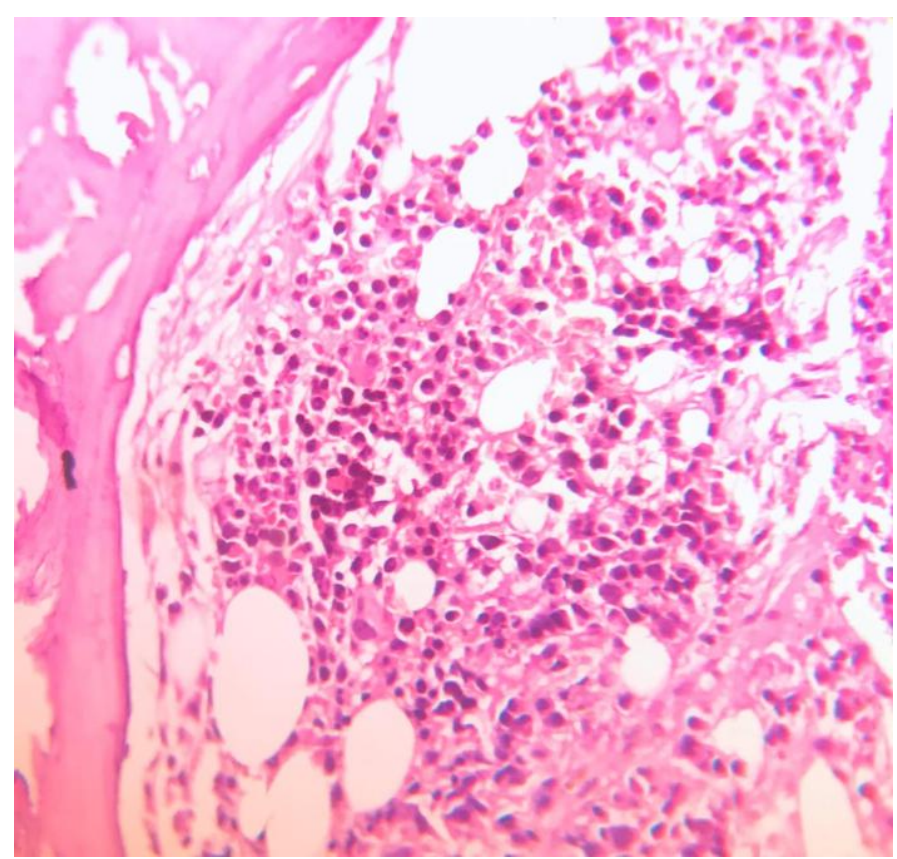

Figure 3: Bone marrow biopsy showing collection of plasma cells.

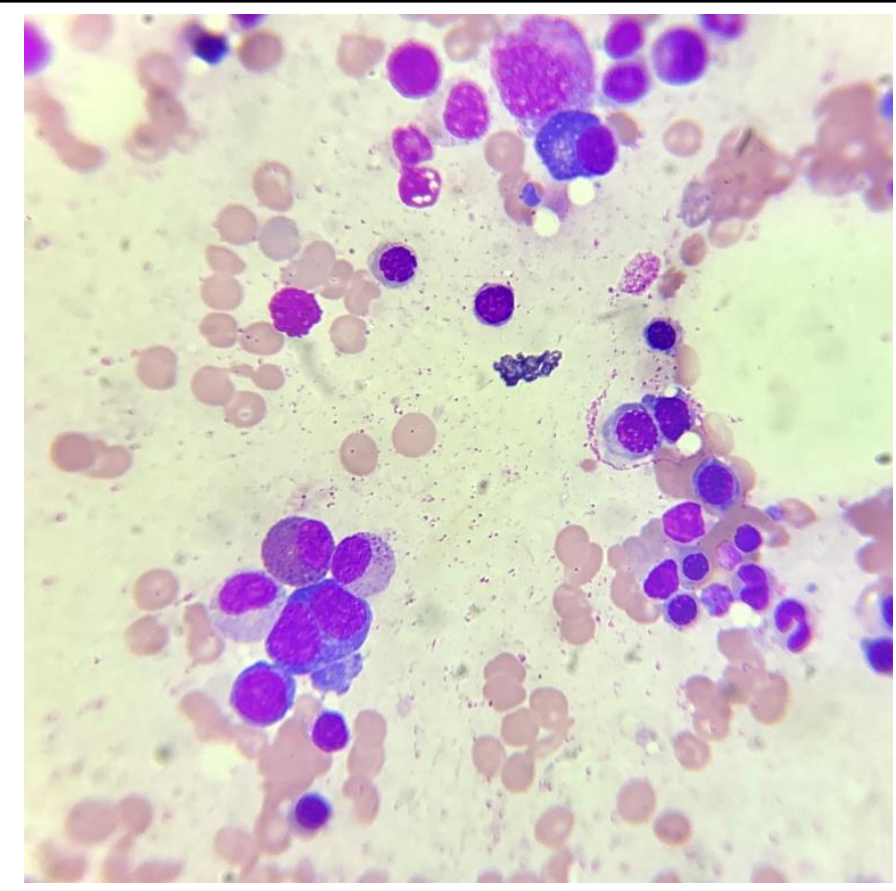

Figure 4: Bone aspiration cytology showing plasma cells.

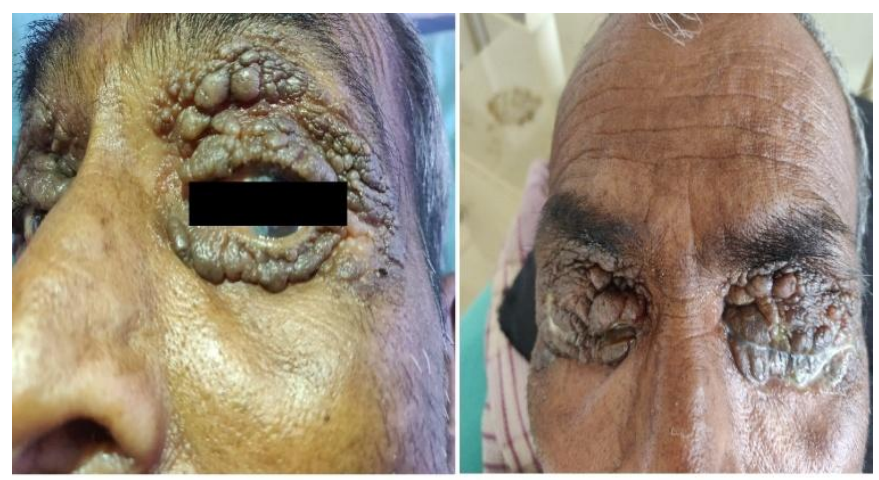

Figure 5: Multiple waxy nodulopapular swellings on both eye lids with purulent discharge

\section{Discussion}

Diagnostic criteria for Multiple Myeloma by International Myeloma Working Group ${ }^{4}$

1. Hypercalcemia: Serum calcium $1 \mathrm{mg} / \mathrm{dL}$ more than the upper limit of normal or more than $11 \mathrm{mg} / \mathrm{dL}$

2. Renal impairment: Serum creatinine more than $2 \mathrm{mg} / \mathrm{dL}$ or creatine clearance less than $40 \mathrm{ml}$ per minute

3. Anemia: Hemoglobin more than $2 \mathrm{~g} / \mathrm{dL}$ below the lower limit of normal or less than $10 \mathrm{~g} / \mathrm{dL}$

4. Bone lesions: One or more osteolytic lesion on X-ray, CT, or PET-CT 
Any one ore more of the following biomarkers of malignancy:

- Clonal bone marrow plasma cell percentage $\geq 60 \%$

- Involved: Uninvolved serum free light chain ratio $\geq 100$

- $\quad>1$ focal lesions on MRI studies

Amyloidosis is a condition in which there is extracellular deposition of misfolded insoluble protein fibrils in the various organs and tissues. Amyloid diseases are grouped based on biochemical composition of the deposited fibrils, site of deposition- systemic or localized, familial or acquired and their clinical presentations.

The following are most commonly described systemic amyloid diseases: a) AL type, Primary Systemic Amyloidosis arising from clonal B cells or Plasma cells due to deposition of Immunoglobulin light chains and are associated with MM or lymphomas. b) AF type, Familial Amyloidosis caused by mutation in the transport protein of thyroid hormone and retinol-binding protein- transthyretin. c) AA type, Secondary Systemic Amyloidosis occurs in the setting of chronic inflammatory conditions due to deposition of Serum amyloid A, a acute phase reactant. d) $\mathrm{A} \beta_{2} \mathrm{M}$ type seen in patients on long term hemodialysis due to deposition of misfloded $\beta_{2}$ Microglobulin.

\section{AL Amyloidosis}

It is the most common type of systemic amyloidosis which is secondary to deposition of Ig light chains and is associated with $\mathrm{MM}$ or B cell lymphomas. It is generally seen after the age of 40 years and usually rapidly progressive and fatal if left untreated. The deposition can occur in any tissue or organ other than central nervous system and the deposits are composed of full light chains or their fragments along with glycosaminoglycans, amyloid p components and metal in ionic forms. The clinical presentation is based on the organ involved with kidneys being the most commonly involved. Cardiac amyloidosis would manifest with cardiac failure secondary to restrictive cardiomyopathy.

Cutaneous amyloidosis can be localized cutaneous amyloidosis or systemic amyloidosis with cutaneous involvement. Cutaneous amyloidosis is seen in $40 \%$ cases with AL type amyloidosis and manifestation depends on site of deposition ${ }^{5}$. Most common forms are petechiae, purpura and ecchymosis and more rarer forms are shiny, waxy, macular, nodulopapular lesions ${ }^{6}$. Our patient presented with nodulopapular lesions around the eye even prior to onset of systemic symptoms. Our patient also had features of amyloid arthropathy of hip joint.

\section{Conclusion}

AL amyloidosis carries poor prognosis. Many a times cutaneous manifestation in systemic amyloidosis may precede systemic manifestations, hence, it is necessary to be familiar with spectrum of cutaneous manifestations of AL amyloidosis and to investigate at the earliest for diagnosis, treatment and prognostication.

\section{Bibliography}

1. Cowan AJ, Allen C, Barac A, Basaleem H, Bensenor I, Curado MP, et al. Global Burden of Multiple Myeloma: A Systematic Analysis for the Global Burden of Disease Study 2016. JAMA Oncol. 2018 Sep 1;4(9):1221-7.

2. Bladé J, Kyle RA. Multiple Myeloma in Young Patients: Clinical Presentation and Treatment Approach. Leuk Lymphoma. 1998 Jan 1;30(5-6):493-501.

3. Kyle RA, Gertz MA, Witzig TE, Lust JA, Lacy MQ, Dispenzieri A, et al. Review of 1027 Patients With Newly Diagnosed Multiple Myeloma. Mayo Clin Proc. 2003 Jan 1;78(1):21-33.

4. Jameson JL, editor. Harrison's principles of internal medicine. Twentieth edition. New York: McGraw-Hill Education; 2018. 2 p. 
5. Saoji V, Chaudhari S, Gohokar D. Primary systemic amyloidosis: Three different presentations. Indian J Dermatol VenereolLeprol. 2009 Jul 1;75(4):394.

6. Wong C-K. Mucocutaneous manifestations in systemic amyloidosis. Clin Dermatol. 1990 Apr 1;8(2):7-12. 